\title{
Selection of rye on leaf-emergence rhythm
}

\author{
R. F. Hoogland
}

Institute for Biological and Chemical Research on Field Crops and Herbage (I.B.S.), P.O. Box 14, Wageningen, The Netherlands

Received 2 December, 1966

\section{Summary}

Proceeding from the wide variability within one variety of winter rye it is shown that the emergence rhythm of the leaves on the main axis is a heritable character. The leaf size is closely correlated to it. This rhythm may be the same before and after ear initiation, viz. initially high and afterwards also high $(\mathrm{H} / \mathrm{H})$, or initially low and afterwards low $(\mathrm{L} / \mathrm{L})$, or different: initially high and afterwards low $(\mathrm{H} / \mathrm{L})$ or the reverse $(\mathrm{L} / \mathrm{H})$.

By using this rhythm four widely different selections may be obtained. Selection on a low rhythm before and after ear initiation (L/L) considerably shortens the straw length and appreciably accelerates ear emergence. The total leaf area need not decrease if during selection special attention is paid to the size of the last leaves. The selection with a high leaf-emergence rhythm before winter generally shows a prostrate growth habit during this period.

\section{Introduction}

Rye is often mentioned as an example of a once fruit bearing allogamous plant which cannot be completely evaluated before flowering (Wellensiek, 1947). This implies that it would be impossible to find a correlation between leaf development and yield, thus eliminating unpromising individuals before flowering. Moreover, the great variability of rye is a handicap in finding such a correlation which may only be obviated by using complex cross-breeding schemes. It is therefore most important to find a less intricate selection method which may be applied before flowering with a more direct result.

Earlier investigations (Hoogland, 1964b) have shown that the leaf-emergence rhythm in rye may vary considerably during the vegetative phase as well as afterwards. This leaf-emergence rhythm is a heritable character (Hoogland, 1961, 1962) and therefore it can be used in breeding work. A certain correlation was also found between the leaf-emergence rhythm and the total leaf area (Hoogland, 1964b). In the mean time investigations have indicated a possible correlation between the leaf area and the productivity of the ear (Hoogland, 1964a). According to Boonstra (1929) the youngest leaves contribute considerably in the seed formation of winter wheat, which probably also holds for other cereal species. 


\section{Method of research}

On 2 October 1960 about 600 seeds of the variety Zelder were sown at equal depth. This early date was chosen to obtain a great number of leaves before winter and a wide spreading of total leaf number. After emergence the rhythm of leaf development was carefully observed. In autumn two groups were distinguished and retained, comprising on the one hand the lowest and on the other hand the highest rhythm of development, viz. on 31 October 4 (or less) and 5 leaves, respectively. Continued selection enlarged the difference in these groups up to 2 leaves on the next leafcounting date just before winter.

By retaining all plants from both groups after winter, a clear survey of their leafemergence rhythm was obtained. After winter the rhythm within both groups again showed a difference. By obtaining from each group plants with an opposite rhythm it was possible to isolate four groups:

Autumn low rhythm (vegetative phase), afterwards low rhythm

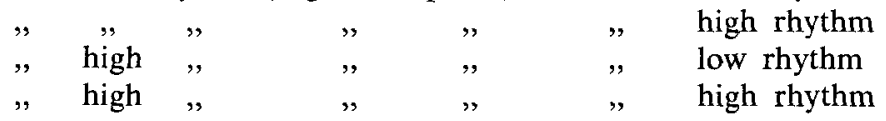

By isolation seed could be obtained from each separate group next autumn; this seed was sown again at equal depth and distance. In the two groups with an initially high rhythm $(\mathrm{H} / \mathrm{H}$ and $\mathrm{H} / \mathrm{L})$ the 5th leaf was marked after the 4th leaf was fully developed in the greater part $(80 \%)$ of the plants. The plants with retarded leaf development were removed. In the group $\mathrm{H} / \mathrm{H}$ this method was continued until the last leaf emerged.

The dates on which the 5th leaf and the subsequent ones were fully developed were recorded. After winter no more plants of the group $H / L$ were removed, but from each plant the leaf-emergence rhythm was accurately recorded. To prevent errors in determining the order of the leaves the youngest leaf visible was always marked; it did not matter so much then if under favourable growing conditions one leaf was skipped. When the ultimate leaf number was known, only the plants with the smallest number of leaves (low rhythm) were maintained. At about the same time the 4th leaf of the plants showing at that moment only 3 fully developed leaves $(80 \%)$ was marked in the groups with an initially low rhythm $(\mathrm{L} / \mathrm{L}$ and $\mathrm{L} / \mathrm{H})$. Those plants showing a distinct lead in leaf-emergence rhythm were removed before winter $(20 \%)$. Of a few plants showing only 2 fully developed leaves the $3 \mathrm{rd}$ leaf was marked. Selection was continued until winter, but after this, all plants of the first group $(\mathrm{L} / \mathrm{L})$ were retained and the emergence dates of the next leaves recorded, until the total leaf number was known. Then the plants with the smallest leaf number were retained for seed production after isolation.

After winter the group $\mathrm{L} / \mathrm{H}$ was treated in the same way as $\mathrm{H} / \mathrm{H}$. To prevent inbreeding the remaining number of plants was not taken too small. The plants in the groups $\mathrm{H} / \mathrm{L}$ and $\mathrm{L} / \mathrm{H}$ were more difficult to recognize than those in the other groups. The first negative selection was very easy; in the two groups with an initially high rhythm a clear distinction could be made (in $\mathrm{H} / \mathrm{H}$ more so than in $H / L$ ) between plants of which the 5th leaf had or had not emerged.

Selection is facilitated by choosing the right moment of selection, viz. the moment at which the percentage of plants with a non-visible 5th leaf is the same as the 
percentage of plants to be retained. All plants with less than 5 leaves may be removed without hesitation.

In the two remaining groups with an initially low rhythm the same method was applied; only, here the clearly lagging plants were selected and recorded; when, well over 3 weeks later, after a few days of mild weather, a second selection was made the 5th leaf was just visible in a part of the plants in group $\mathrm{L} / \mathrm{L}$. By using this clear difference in rhythm and removing these plants much labour could be saved. This did not work in group $\mathrm{L} / \mathrm{H}$, because the selection was less rigorous. After each removal of undesirable plants the leaf number of the remaining plants was again the same. Though invisible, the difference in rhythm remains, and dependent on weather conditions sooner or later clear differences in leaf number will occur again. By experimentally counting both types of plant in a few rows the percentages of both groups can be approximated. The total number of seeds sown determines the percentage of plants to be removed or retained.

After this first and for $\mathrm{L} / \mathrm{L}$ second negative selection there remained in the 4 groups $\mathrm{H} / \mathrm{H}, \mathrm{H} / \mathrm{L}, \mathrm{L} / \mathrm{H}$ and $\mathrm{L} / \mathrm{L} 186,250,360$ and 226 plants, respectively. The wide variation in number is caused by the fact that the two centre groups in a population are always present to a larger extent. Fig. 1 shows the other possibilities besides those of the 4 groups described above. This figure schematically reflects the selection method on leaf-emergence rhythm, viz. the start in $1960 / 1961$ and the results obtained in $1964 / 1965$.

The uninterrupted lines show the plants belonging to the 4 groups discussed. The interrupted lines show the possibilities not investigated in this research, i.e. the plants removed.
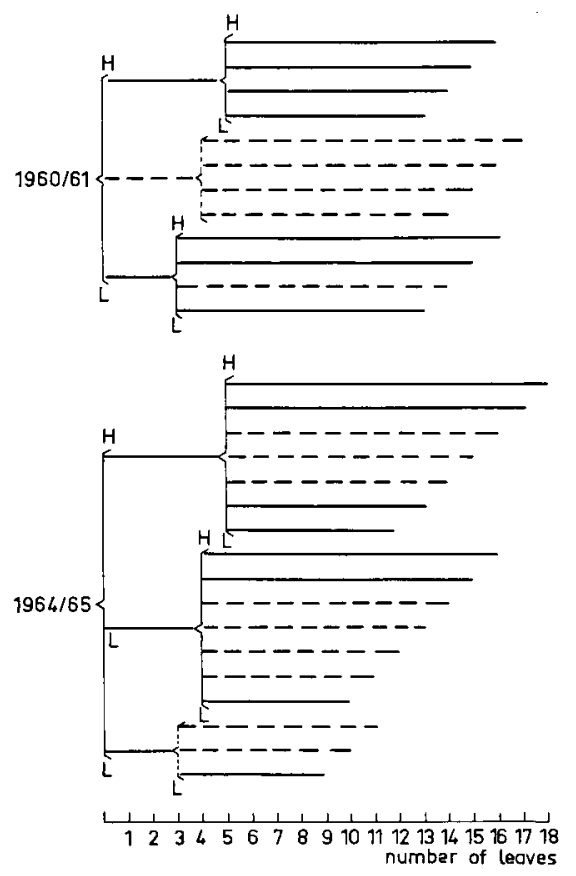

Fig. 1 Results of a 5-year selection on leafemergence rhythm shown in a diagram.

- Plants retained in this investigation

-. - Plants removed in time and the possibilities not used 


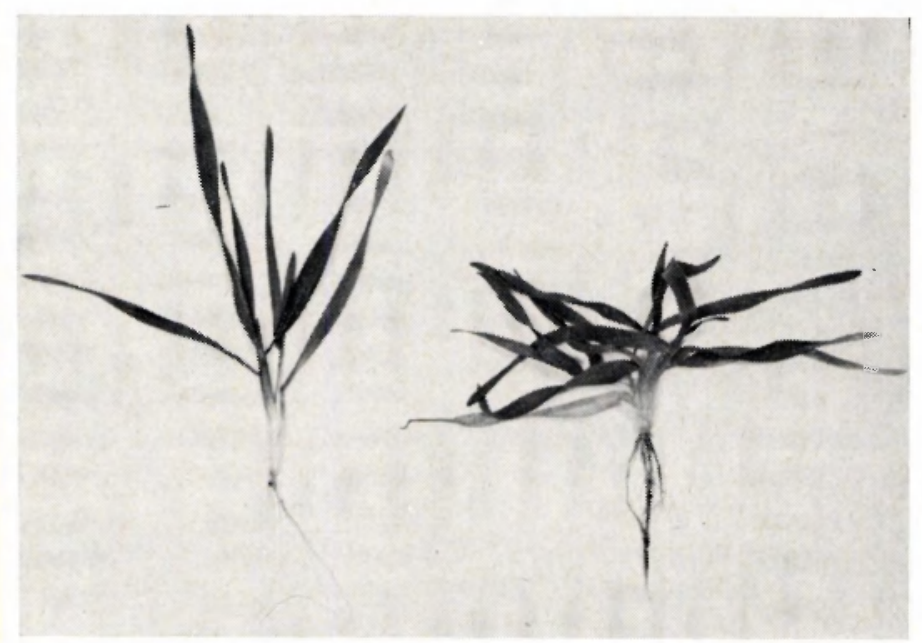

Fig. 2 Difference in growth habit between $L / L$ (left) and $H_{i} H$ (right).

\section{Results}

Leaf-emergence rhythm of the different selections

Table 1 reflects an outline of the selection on leaf-emergence rhythm in the variety Zelder started in 1960. In the two extreme groups the difference in the total number of leaves increased from $2-3$ to 8 , while the number of plants doubled. In $\mathrm{H} / \mathrm{L}$ and $\mathrm{L} / \mathrm{H}$ the results are less spectacular, because of the greater variability. Since the plants were selected in opposite directions during the vegetative and reproductive phases, the differencce cannot be so large; in the two extreme groups the selection always is in the same direction either high or low.

The groups $\mathrm{H} / \mathrm{H}$ and $\mathrm{L} / \mathrm{L}$ show a certain homogeneity, especially in group $\mathrm{L} / \mathrm{L}$ in the 4th year. An appreciable part of the plants had a total leaf number of 10 and 11 , so that a minimum of 10 leaves sufficed. Plants with 9 leaves did not yet occur that year.

Correlation of the leaf-emergence rhythm to growth habit and ear initiation

1) In the autumn of 1964 a striking difference in the growth habits was observed. In the groups with an initially high rhythm almost all plants showed a 'prostrate' growth habit and those in the other two groups an 'erect' growth habit ${ }^{1}$ (Fig. 2).

Group $\mathrm{L} / \mathrm{L}$ did not show any exception. In group $\mathrm{H} / \mathrm{H}$ the extent of 'prostrate' growth was closely correlated to the rhythm; completely 'prostrate' plants also showed the highest rhythm, i.e. the youngest leaf was most fully developed in these plants. Fig. 3 also shows that the difference in tillering was considerable; in the groups with

1 Recently it was found that the group $\mathrm{H} / \mathrm{H}$ also comprised plants with 'erect' growth which was heritable, and the group L/L plants with 'prostrate' growth (spring 1966). The growth habit (erect or prostrate) is therefore independent of the leaf emergence rhythm. 


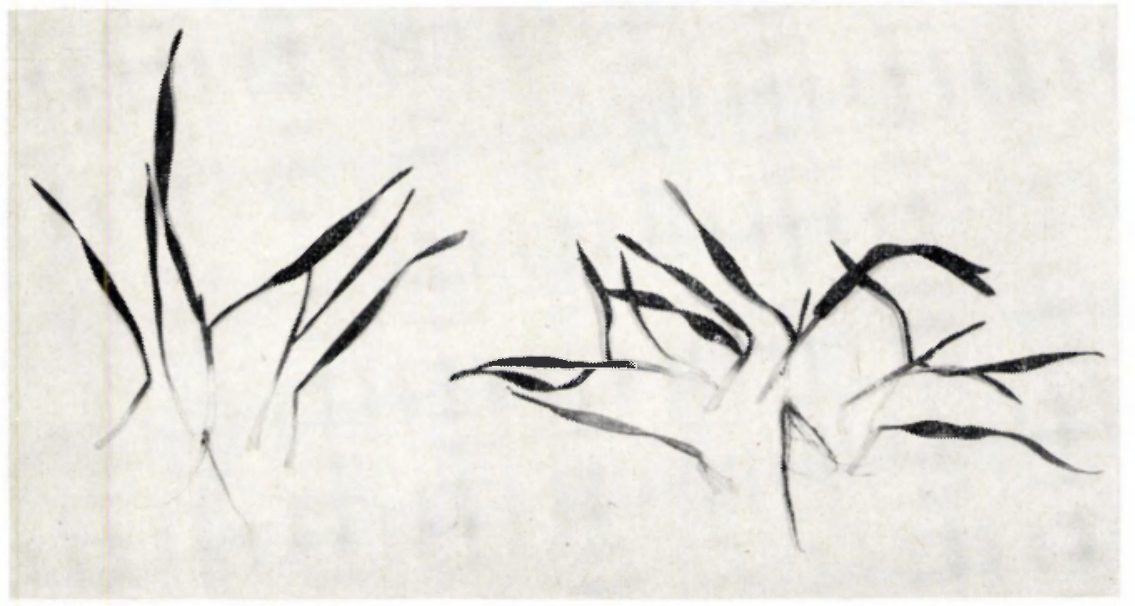

Fig. 3 Difference in tillering between $L / L$ (left) and $H H$ (right).

Table I Outline and results of 5 years selection on leaf-emergence rhythm in the variety Zelder

\begin{tabular}{|c|c|c|c|c|c|c|c|c|c|}
\hline \multirow[t]{2}{*}{ Sowing } & \multirow[t]{2}{*}{ date } & \multicolumn{2}{|c|}{ Number of leaves } & \multicolumn{2}{|c|}{ Number of plants } & \multirow[t]{2}{*}{ Group } & \multicolumn{3}{|c|}{ Retained } \\
\hline & & $\begin{array}{l}\text { at the start } \\
\text { of counting }\end{array}$ & total & beginning & end & & & & \\
\hline 2 Oct. & 1960 & $\begin{array}{r}5 \\
5 \\
3 \\
3-4\end{array}$ & $\begin{array}{c}15-16 \\
13-14 \\
15-16 \\
13\end{array}$ & ca. 600 & $\begin{array}{l}17 \\
11 \\
17 \\
15\end{array}$ & $\begin{array}{l}\mathrm{H} / \mathrm{H} \\
\mathrm{H} / \mathrm{L} \\
\mathrm{L} / \mathbf{H} \\
\mathbf{L} / \mathbf{L}\end{array}$ & & & . \\
\hline 29 Sept. & 1961 & $\begin{array}{l}5 \\
5 \\
4 \\
4\end{array}$ & $\begin{array}{l}14 \\
12 \\
14 \\
12\end{array}$ & ca. 600 & $\begin{array}{l}17 \\
22 \\
17 \\
22\end{array}$ & $\begin{array}{l}\mathrm{H} / \mathrm{H} \\
\mathrm{H} / \mathrm{L} \\
\mathrm{L} / \mathbf{H} \\
\mathbf{L} / \mathbf{L}\end{array}$ & & & \\
\hline 1 Oct. & 1962 & $\begin{array}{l}5 \\
5 \\
4 \\
4\end{array}$ & $\begin{array}{c}14-15 \\
12 \\
13 \\
10\end{array}$ & ca. 600 & $\begin{array}{l}28 \\
42 \\
22 \\
30\end{array}$ & $\begin{array}{l}\mathrm{H} / \mathrm{H} \\
\mathrm{H} / \mathrm{L} \\
\mathbf{L} / \mathbf{H} \\
\mathbf{L} / \mathbf{L}\end{array}$ & & & \\
\hline 8 Oct. & 1963 & $\begin{array}{l}5 \\
5 \\
4 \\
4\end{array}$ & $\begin{array}{c}16-17 \\
12 \\
14 \\
10\end{array}$ & ca. 600 & $\begin{array}{l}31 \\
31 \\
29 \\
48\end{array}$ & $\begin{array}{l}\mathrm{H} / \mathrm{H} \\
\mathrm{H} / \mathbf{L} \\
\mathrm{L} / \mathbf{H} \\
\mathbf{L} / \mathbf{L}\end{array}$ & & & \\
\hline 29 Sept. & 1964 & 5 & $17-18$ & ca. 700 & 33 & $\mathbf{H} / \mathbf{H}$ & $\begin{array}{r}22 \\
2\end{array}$ & $\begin{array}{ll}\text { of } 17 \\
\Rightarrow 18\end{array}$ & $\begin{array}{c}\text { leaves } \\
\text {, }\end{array}$ \\
\hline & & 5 & $12-13$ & & 51 & $\mathrm{H} / \mathrm{L}$ & $\begin{array}{l}16 \\
12\end{array}$ & $\begin{array}{ll}\text { " } 12 \\
\text { " } 13\end{array}$ & ", \\
\hline & & $4 *$ & $15-16$ & & 42 & $\mathbf{L} / \mathbf{H}$ & $\begin{array}{r}18 \\
1\end{array}$ & $\begin{array}{ll}\Rightarrow & 15 \\
" 16\end{array}$ & $"$ \\
\hline & & $4 *$ & $9-10$ & & 34 & $\mathbf{L} / \mathbf{L}$ & $\begin{array}{r}2 \\
23\end{array}$ & $\begin{array}{lr} & 9 \\
& \end{array}$ & $"$ \\
\hline
\end{tabular}

* There were a few plants with 3 leaves 
a high rhythm in autumn, i.e. the 'prostrate' growth habit, the rate of tillering was higher.

2) Ear initiation was also closely correlated to the rhythm and accordingly with the growth habit. The slower the rhythm in autumn the more rapid the ear initiation, which suggests that the growth habit may run parallel to the cold requirement.

Correlation of the leaf-emergence rhythm to the leaf area and number of spikelets Selection on the smallest number of leaves might involve a considerable decrease in the total assimilating leaf area, associated with a low yield. To prevent a decrease in the total leaf area, from the start in 1960 onwards only the plants with the largest last leaf were retained of the two groups with a low rhythm after winter $(\mathrm{H} / \mathrm{L}$ and $\mathrm{L} / \mathrm{L}$ ). In this group it turned out easy to obtain plants with a flag leaf as large as the preceding one. This selection method resulted in two strikingly large last leaves in the group $\mathrm{L} / \mathrm{L}$ and to a less extent also in $\mathrm{H} / \mathrm{L}$. (In the groups $\mathrm{H} / \mathrm{H}$ and $\mathrm{L} / \mathrm{H}$ the size of the last two leaves was also increased by selection.) The possibility of continued selection on large last leaves indicates that leaf size is a heritable character. Although at the beginning of the experiment in autumn, the plants were not selected on leaf size, the leaves grown before winter on the plants in $\mathrm{L} / \mathrm{L}$ were considerably larger than those on the plants in $\mathrm{H} / \mathrm{H}$. The impression is also gained that the leaf size increases as the plant has a more 'erect' growth habit. Since the plants in the groups $\mathrm{H} / \mathrm{L}$ and $\mathrm{L} / \mathrm{L}$ were selected on large last leaves, it is suggested that there might be a relation between the leaf size of the first and last leaves as well as between the individual leaves.

According to Wittenrood (1959) plant size and ear size in wheat are related at the moment of ear initiation. It may be assumed that this also holds for rye. The leaf area is related to the emergence rate, resulting in the number of spikelets - determined early in spring before heading is completed - being related to this rate up to the end of ear initiation. This should imply that plants with an initially high rhythm, viz. $\mathbf{H} / \mathbf{H}$ and $H / L$, may show a favourable ear initiation. Group $\mathbf{H} / \mathbf{H}$ is unsuitable for practice because of its late heading, resulting from the great number of leaves to be formed after winter. $\mathrm{H} / \mathrm{L}$, on the contrary, was selected on the least possible number of leaves after winter, resulting in shorter straw length and earlier heading, and seems to offer more possibilities. Since plants with an initially low rhythm show considerably larger leaves in autumn after some years of selection especially group $\mathrm{L} / \mathrm{L}$ - and the leaf area at the time of ear initiation is larger compared to plants with an initially high rhythm (Table 2), plants of this group might offer still better prospects. These plants combine the most favourable leaf area during heading and after flowering with short straw and earliness.

Table 2 Average leaf area in 1965

\begin{tabular}{lrrrrr} 
& \multicolumn{4}{c}{ Average leaf area * $(\%)$} & Average \\
\cline { 2 - 5 } No, of leaf : & \multicolumn{1}{c}{1} & 2 & 3 & 4 & \\
$\mathrm{H} / \mathrm{H}$ & 79 & 87 & 82 & 162 & 93 \\
$\mathrm{~L} / \mathrm{L}$ & 131 & 159 & 142 & 67 & 134 \\
& & & & &
\end{tabular}




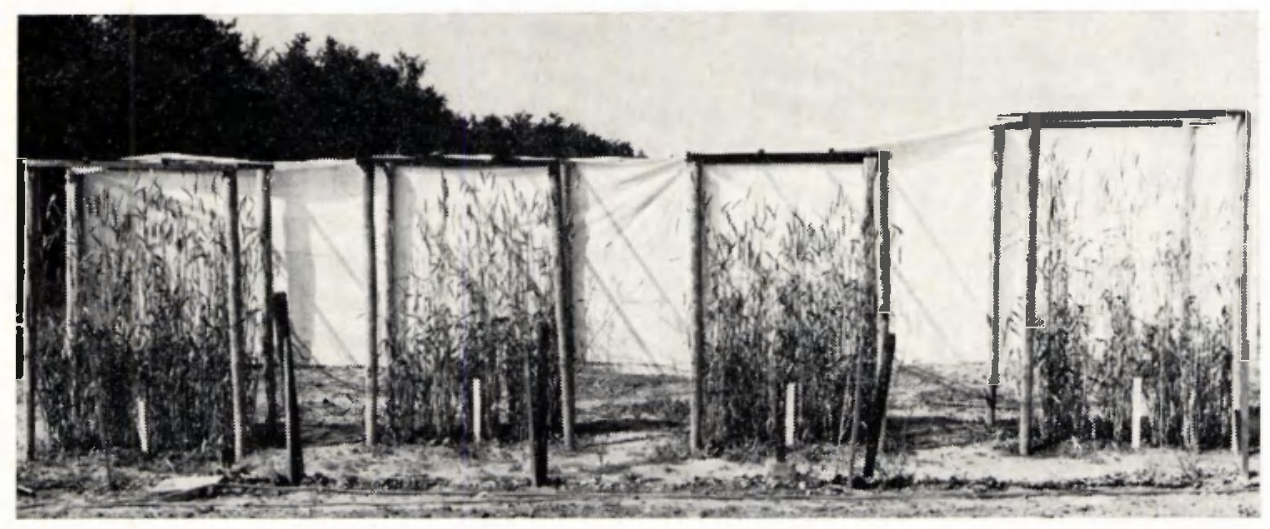

Fig. 4 Four selections in 1964. From left to right: $H, L, L ; H, L / L$ and $H, H$.

Table 3 Kernel and straw yield and grain/straw ratio in 1965

\begin{tabular}{lccc}
\hline & \multicolumn{2}{c}{ Yield $(\mathrm{kg} /$ are $)$} & $\begin{array}{c}\text { Ratio } \\
\text { grain } / \text { straw }\end{array}$ \\
\cline { 2 - 3 } & kernel & straw & \\
Zelder & 57.3 & 84.3 & 0.68 \\
H/H & 52.2 & 85.0 & 0.61 \\
L/L & 54.2 & 75.8 & 0.72 \\
\hline
\end{tabular}

Correlation of the leaf-emergence rhythm to the emergence date of the last leaf and stem length

In 1964 it was noticed that the emergence date of the last leaf deviated rather widely in the groups $\mathrm{H} / \mathrm{H}$ and $\mathrm{L} / \mathrm{L}$. In the last-mentioned group it was about 10 days earlier. The straw lengths differed widely as well, strikingly short in $\mathrm{L} / \mathrm{L}$ and long in $\mathrm{H} / \mathrm{H}$ (Fig. 4). The two other groups were intermediate. Because part of the plants of each group had been replanted before flowering, no data were collected on the straw length. Since nowadays it is considered a genuine improvement in plant breeding to obtain plants with shorter straw the types $\mathrm{H} / \mathrm{L}$ and $\mathrm{L} / \mathrm{L}$ should be considered the most promising ${ }^{2}$.

\section{Preliminary observations on productivity}

To obtain some idea on the production as a field crop a small informative experiment, in which the groups $\mathrm{H} / \mathrm{H}$ and $\mathrm{L} / \mathrm{L}$ were compared with the parent variety Zelder, was started in the autumn of 1963. Group L/L showed a considerably lower straw yield and shorter straw, it was earlier than Zelder, but the kernel yield was equal. Group $\mathrm{H} / \mathrm{H}$ was distinctly later; as a result of complete lodging the kernel yield, straw yield and especially the kernel quality were less.

2 In the mean time the 'prostrate' types of the groups $\mathrm{H} / \mathrm{L}$ and $\mathrm{L} / \mathrm{L}$ seem most promising (summer 1967). 
The next year there was sufficient sowing seed by multiplication of $\mathrm{H} / \mathrm{H}$ and $\mathrm{L} / \mathrm{L}$ to start a more elaborate field experiment. In this experiment like in the preceding year $\mathrm{L} / \mathrm{L}$ was distinctly shorter and earlier than the parent variety Zelder. There was a clear difference in ear number; in $\mathrm{L} / \mathrm{L}$ it was about $5 \%$ below and in $\mathrm{H} / \mathrm{H}$ about $5 \%$ above that of Zelder. The ears were clearly heavier in $\mathrm{L} / \mathrm{L}$. Although $\mathrm{H} / \mathrm{H}$ had the lowest kernel yield the differences were not reliable (Table 3).

The straw yield was reliably lower in $\mathrm{L} / \mathrm{L}$ and was some $10 \%$ below that of Zelder and $\mathrm{H} / \mathrm{H}$, the difference between the latter two was rather slight. The total production (grain + straw) per hectare with the same plant number is lower in $\mathbf{L} / \mathbf{L}$. This may be explained by the shorter total growing period. Since the lower ear number in $\mathbf{L} / \mathbf{L}$ is caused by less tillering, a small increase in the sowing seed may increase the grain yield.

\section{References}

Boonstra, A. E. H. R., 1929. Invloed van de verschillende assimilerende delen op de korrelproductie bij wilhelminatarwe. Mededel. Landbouwhogeschool Wageningen, 33, Verhandeling 3.

Hoogland, R. F., 1961. Selection of rye by means of leaf counting. Euphytica, 10: 101-108.

Hoogland, R. F., 1962. Selection of rye by means of leaf counting. II. Further data. Euphytica, 11 : 209-212.

Hoogland, R. F., 1964a. Relation between leaf number and final leaf area of rye. Neth. J. Agr. Sci., $12: 30-39$.

Hoogland, R. F., 1964b. The difference in development rate of rye in relation to the number of spikelets per ear. Neth. J. Agr. Sci., $12: 297-309$.

Wellensiek, S. J., 1947. Grondslagen der algemene plantenveredeling. Tjeenk Willink, Haarlem. 2nd ed., pp. 470-509.

Wittenrood, H. G., 1959. Correlatie tussen plant- en aargrootte ten tijde van de aaraanleg bij tarwe. Jaarb. I.B.S., Wageningen, pp. 135-146. 